\title{
FATORES GENÉTICOS E AMBIENTAIS ENVOLVIDOS NA CARCINOGÊNESE GÁSTRICA
}

\author{
Ana Cristina Gobbo CÉSAR, Ana Elizabete SILVA e \\ Eloiza Helena TAJARA
}

RESUMO - Racional - O câncer de estômago é o segundo tipo mais comum de neoplasia no mundo. A carcinogênese de estômago é processo de múltiplos passos, podendo manifestar-se em várias etapas como gastrite superficial, gastrite atrófica crônica, metaplasia intestinal, displasia e, finalmente, como um carcinoma. Essas condições costumam ser seqüenciais e ocorrer num período de muitos anos como resultado da exposição a uma variedade de fatores endógenos e exógenos, que causam alterações genéticas. Os recentes avanços da genética molecular têm mostrado que o acúmulo dessas várias anormalidades, incluindo a ativação de oncogenes e a inativação de genes supressores de tumores, resultam no desenvolvimento do câncer. Alterações genéticas descritas em carcinomas gástricos incluem amplificações e mutações dos genes $c-E R B B 2, K-R A S, c-M E T$ e TP53. O ganho de cromossomos também foi encontrado em várias combinações com perda de outros cromossomos e pode estar associado com a expressão elevada de oncogenes, que contribuem com a progressão tumoral. Conclusão - Essas mudanças genéticas em carcinomas evidenciam o processo de múltiplas etapas da carcinogênese gástrica, por meio do acúmulo de uma série de alterações.

DESCRITORES - Neoplasias gástricas, genética.

O câncer de estômago é o segundo tipo mais comum de neoplasia em incidência e mortalidade, sendo duas vezes mais freqüente no sexo masculino do que no feminino(1), principalmente entre os idosos. A freqüência na população é baixa aos 40 anos e aumenta progressivamente com a idade, até atingir seu valor mais elevado por volta dos 70 anos nos homens e pouco mais tarde nas mulheres ${ }^{(14)}$.

As estatísticas mundiais mostram distinta variação geográfica ${ }^{(14)}$. Por exemplo, taxas elevadas são encontradas no Japão, Chile, China, Portugal e Rússia enquanto, em outros países, essas taxas têm declinado, como na França, Reino Unido, Austrália, Canadá e Estados Unidos. No Brasil, as estimativas para 2002 apontaram para mais de 20 mil casos novos e 11 mil óbitos ${ }^{(27)}$ sendo, na cidade de São Paulo, o tipo de neoplasia mais comum entre os homens e o terceiro entre as mulheres ${ }^{(1)}$.
O prognóstico do câncer gástrico avançado é extremamente pobre, com taxas de sobrevivência de 5 anos entre $5 \%$ a $15 \%{ }^{(5)}$. Tal fato é conseqüência do diagnóstico, na maioria dos casos, ser realizado em estágios avançados e dessa doença mostrar taxa de recurrência próxima a $80 \%$, mesmo quando é realizada a gastrectomia ${ }^{(14)}$. O prognóstico depende da extensão da invasão do câncer, do comprometimento das estruturas adjacentes e da presença ou ausência de metástases em nódulos linfáticos e outros órgãos distantes.

A tumorigênese gástrica, assim como de outros órgãos, é processo de múltiplas etapas que, clinicamente, pode manifestar-se como gastrite, atrofia gástrica, ulcerações, metaplasia intestinal, displasia e, finalmente, como neoplasia maligna $^{(11)}$. Essas condições costumam ser seqüenciais e ocorrer num período de muitos anos, como resultado da exposição a uma variedade de fatores endógenos e exógenos. As principais

Departamento de Biologia, Universidade Estadual Paulista - UNESP, São José do Rio Preto, SP.

Endereço para correspondência: Dra. Ana Elizabete Silva - Rua Cristóvão Colombo, 2265 - Bairro Jardim Nazareth - 15054-000 - São José do Rio Preto, SP. 
conseqüências da ação de tais fatores são as mutações somáticas, como em oncogenes e genes supressores de tumores, que conferem às células vantagens seletivas de proliferação ${ }^{(10)}$.

A gastrite é a lesão que mais freqüentemente afeta o estômago e é definida como uma inflamação da mucosa gástrica. A gastrite aguda é raramente observada em biopsia de rotina, por causa de sua característica transitória. Na gastrite crônica, as lesões vão desde processo inflamatório superficial, até a atrofia do epitélio, que é evidenciada pela perda significativa de estruturas glandulares e mostrase, algumas vezes, associada à metaplasia intestinal. Aproximadamente $10 \%$ dos pacientes com atrofia gástrica desenvolvem carcinoma em período de 15 anos $^{(9)}$, sendo por isso, considerada lesão pré-maligna ${ }^{(20)}$.

Em 60\%-80\% dos casos, existe associação entre gastrite e úlcera gástrica. Vários dados da literatura mostram que entre os fatores etiológicos da úlcera estão defeitos primários na resistência da mucosa ou deficiências quantitativas ou qualitativas do seu muco, além de alguns fatores ambientais, como a ingestão de aspirina não-tamponada, álcool e medicamentos antiinflamatórios não-esteróides ${ }^{(2,11)}$.

Os pacientes com úlceras apresentam níveis reduzidos ou normais de ácido gástrico. HANSSON et al. ${ }^{(22)}$ mostraram que, entre aqueles com redução na produção desse ácido e pangastrite, existe risco maior de câncer do que nos pacientes com úlcera duodenal, que têm níveis elevados de ácido e geralmente também exibem gastrite, predominantemente na região antral. É importante referir que a ressecção gástrica como tratamento da úlcera não diminui esse risco ${ }^{(55)}$.

Eventualmente, acompanhando uma gastrite ou durante o processo de cicatrização da mucosa gástrica, é observada a metaplasia intestinal, decorrente da transformação do epitélio de revestimento e glandular em células absortivas colunares metaplásicas intercaladas por células caliciformes de morfologia intestinal. Essa lesão está associada à infecção pelo Helicobacter pylori ${ }^{(19)}$ e, embora as características do intestino delgado predominem, em algumas situações as características do epitélio colônico estão presentes, originando a metaplasia do tipo incompleto, que é o mais relacionado ao câncer gástrico ${ }^{(30)}$.

Com gastrite crônica de longa duração, o epitélio desenvolve alterações citológicas, incluindo as de tamanho, formato e orientação das células epiteliais com atipia dos núcleos. Essas alterações displásicas podem se tornar tão graves a ponto de constituírem um carcinoma in situ ${ }^{(11,34)}$, principalmente do tipo intestinal proveniente de formas atróficas de gastrite. Já o tipo difuso surge originalmente, sem evolução por meio de displasia.

O adenocarcinoma representa $90 \%-95 \%$ dos casos de neoplasias malignas do estômago ${ }^{(11)}$, sendo classificado com base em aspectos histopatológicos e clínicos em dois tipos: intestinal e difuso ${ }^{(61)}$. As lesões tipo intestinal são as mais freqüentes, bem diferenciadas, dependentes de fatores ambientais e associadas com a presença de lesões pré-cancerosas, como gastrite crônica, atrofia gástrica, metaplasia intestinal e displasia ${ }^{(57)}$. São encontradas predominan- temente em homens e em indivíduos mais idosos. O tipo difuso é pouco diferenciado, tem prognóstico ruim e não está associado a lesões pré-cancerosas ${ }^{(59)}$. É pouco mais freqüente em mulheres e pacientes jovens e tem alta ocorrência familial, principalmente entre indivíduos com tipo sangüíneo $\mathrm{A}^{(14)}$.

Diferenças nos critérios de diagnóstico do câncer gástrico inicial entre patologistas japoneses e ocidentais, resultam na falta de entendimento por parte dos clínicos. Segundo MING e HIROTA ${ }^{(42)}$, que exemplificam a opinião de autores ocidentais, a maioria dos carcinomas gástricos são diagnosticados após 1 ano da presença de displasia, sugerindo que o câncer já estava presente no momento da detecção dessa lesão pré-cancerosa. Portanto, ambas as lesões ocorreriam concomitantemente e o desenvolvimento do carcinoma seria mais freqüentemente em áreas com displasia grave. Já na opinião dos patologistas japoneses, a gastrite atrófica com metaplasia evoluiria diretamente para o câncer sem a etapa de displasia, sendo bem representada no trabalho fundamental de NAKAMURA et al. ${ }^{(45)}$.

\section{FATORES ETIOLÓGICOS DO CÂNCER GÁSTRICO}

Existem muitos dados epidemiológicos sugerindo que fatores genéticos e ambientais têm papel importante na etiologia do câncer gástrico. Entre esses últimos, estão o consumo elevado de sal, álcool, cirurgia gástrica anterior, infecção pelo $H$. pylori e história de lesões benignas $^{(1,11,14)}$. Existem também indicações de que a ingestão ou a formação intragástrica de compostos nitrosos ou outras substâncias genotóxicas, assim como o refluxo de bile em indivíduos com gastriteH. pylori positiva, induzem ao aparecimento da metaplasia intestinal e de lesões neoplásicas ${ }^{(12,39,47)}$

No caso de compostos nitrogenados e seus metabólitos, acreditase que sua ação esteja relacionada com a inibição de vitamina $\mathrm{C}$ e de outros antioxidantes que protegem o $\mathrm{DNA}^{(14,35,70)}$. São capazes de provocar a desaminação de purinas e pirimidinas do DNA, do mesmo modo que o óxido nitroso, já referido como responsável por mutações de ponto no gene supressor de tumor TP53 ${ }^{(52)}$

Ao contrário desses compostos, os carotenóides, as vitaminas $\mathrm{C}$ e E, o folato e o selênio presentes em frutas e vegetais estão relacionados à diminuição no risco de aparecimento do câncer gástrico ${ }^{(1)}$.

Fator ambiental bastante estudado é a presença do $H$. pylori, considerado o principal agente etiológico em mais de $95 \%$ das gastrites crônicas e responsável pelo aumento do risco de câncer em até 9 vezes $^{(37)}$. É reconhecido como agente desencadeante de diferentes alterações gástricas, como inflamação crônica assintomática, dispepsia, úlcera, adenocarcinomas e linfomas ${ }^{(40,66)}$. Entretanto, a infecção pelo H. pylori parece não ser suficiente para o desenvolvimento do câncer, cujo risco é de apenas $1 \%$ entre os indivíduos infectados. Na África, por exemplo, a infecção por essa bactéria é observada em crianças de pouca idade, mas nem por isso o câncer gástrico é comum nesse 
país $^{(25,58)}$. Apesar disso, $60 \%-80 \%$ dos casos de neoplasia mostram a presença dessa bactéria ${ }^{(37)}$.

O conhecimento sobre o papel do H. pylori na tumorigênese ainda é incompleto. Sabe-se que essa bactéria secreta urease, enzima responsável pela produção de amônia, além de proteases e fosfolipases, que degradam as glicoproteínas presentes na mucosa gástrica e danificam suas células ${ }^{(11)}$. Outra característica importante é a virulência dessa bactéria, pois existe forte associação entre cepas $H$. pylori-cagA positivas e ulceração gástrica. $\mathrm{O}$ gene cagA (cytotoxinassociated gene) faz parte da chamada ilha de patogenicidade cag, cujos genes expressam proteínas do sistema de secreção tipo IV, capazes de transferir produtos bacterianos, incluindo a proteína cagA, para dentro das células do hospedeiro.
O segundo gene relacionado à virulência, o vacA, é responsável pela codificação de uma citotoxina vacuolizante e apresenta ampla diversidade alélica. As isoformas descritas incluem s1a, s1b, s1c, s2, $\mathrm{m} 1, \mathrm{~m} 1 \mathrm{a}, \mathrm{m} 1 *, \mathrm{~m} 1-\mathrm{m} 2 *, \mathrm{~m} 2 \mathrm{a}$ e $\mathrm{m} 2 \mathrm{~b}$, algumas delas com maior virulência, como s1/m1. Existem relatos de que a associação da variante s1a ao produto do gene $\operatorname{cagA}$ é responsável por processo inflamatório grave na mucosa gástrica ${ }^{(3)}$.

O gene iceA também tem sido estudado em cepas de $H$. pylori, sendo suas principais variantes alélicas a iceA1 e a iceA2. A função desses subtipos ainda não está clara. A expressão do alelo iceAl é regulada pelo contato entre o $H$. pylori e as células epiteliais do hospedeiro e alguns dados sugerem sua participação no desenvolvimento de ulceração péptica ${ }^{(50,67)}$, enquanto outros não ${ }^{(28)}$.

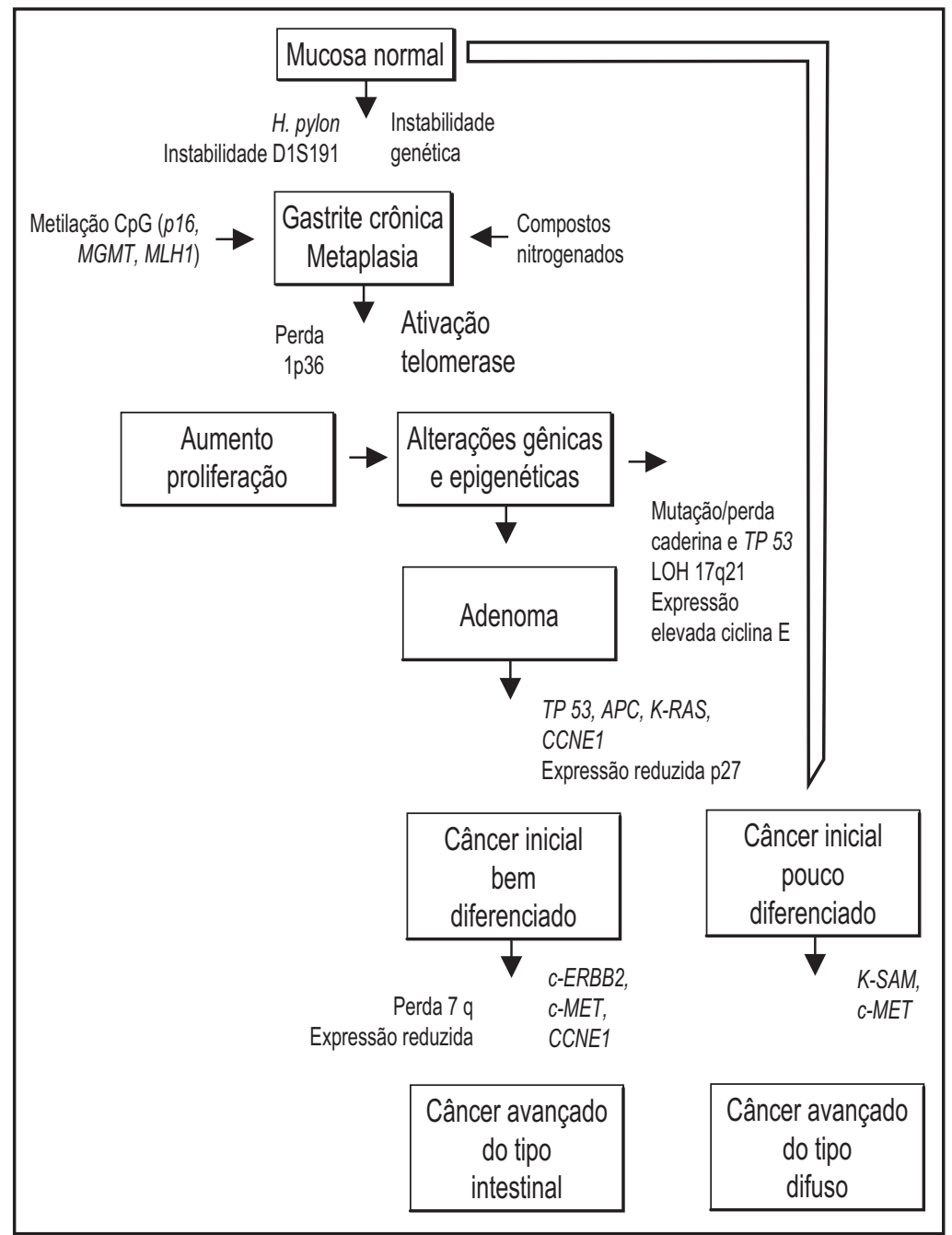

FIGURA 1 - Progressão maligna do adenocarcinoma tipo intestinal e difuso com as alterações genéticas e epigenéticas associadas (TAHARA ${ }^{(61)}$ e YASUI et al. ${ }^{(68,69)}$ ) 
Quanto aos fatores genéticos na tumorigênese gástrica, há indicações de que apenas $4 \%$ dos casos sejam familiais ${ }^{(11)}$. Apoiando esses dados estão os estudos sobre as variações na incidência da doença em migrantes em decorrência de mudanças ambientais, principalmente dieta e fatores culturais. Na China, a freqüência de câncer de estômago em homens foi 4 a 6 vezes mais elevada, quando comparada aos migrantes chineses residentes nos $\mathrm{EUA}^{(1)}$.

\section{ALTERAÇÕES CROMOSSÔMICAS E GÊNICAS ENVOLVIDAS NA CARCINOGÊNESE GÁSTRICA}

O desenvolvimento de novos métodos de diagnóstico, prevenção e tratamento tem contribuído para a redução do câncer gástrico. Todavia, para que ocorra maior progresso nessa área, ainda é necessário compreender melhor os mecanismos envolvidos nas várias etapas do processo tumorigênico ${ }^{(21)}$.

No modelo proposto por FEARON e VOGELSTEIN ${ }^{(17)}$, a carcinogênese gastrointestinal é considerada como resultado do processo de múltiplos passos, no qual anormalidades morfológicas são acompanhadas por acúmulo progressivo de alterações genéticas. No caso especial do câncer gástrico, é observada elevada heterogeneidade nos padrões histológicos e nos genótipos celulares ${ }^{(6)}$, com crescente complexidade dos fenótipos benignos até os malignos (Figura 1). Por exemplo, são referidas perdas da região do braço curto do cromossomo 17 (17p) em 43\% dos adenomas e em $67 \%$ dos carcinomas $^{(33)}$ e perda de heterozigosidade (processo que compreende a conversão do estado heterozigoto para homozigoto em função da perda de um dos alelos) em relação ao gene de reparo do DNA $h M S H 2$ e aos supressores de tumor APC e TP53 em $45 \%$ das metaplasias e em $73 \%$ dos adenocarcinomas ${ }^{(31)}$

Os mecanismos moleculares associados à etiologia do tumor gástrico incluem alterações em vários genes. Por exemplo, no tipo intestinal, ocorrem principalmente amplificações em $c$-ERBB2, $c$-MET e ciclina $E$, mutações no $K-R A S$, inativação do $A P C$, TP53, p16, MGMT e $M L H 1$, perda de heterozigosidade (LOH) do $T P 73$ e redução na expressão das proteínas p27 e nm23, enquanto no tipo difuso, são citadas redução ou perda de função das caderinas, inativação do TP53, LOH da região 17q21, amplificação dos genes $K$-SAM, $c$-MET e ciclina $E$ e redução na expressão das proteínas p27 e nm23 $3^{(8,15,41,44,49,54,63,64,68,69,71)}$.

Os genes citados codificam receptores de membrana relacionados com a transdução de mensagens ao núcleo $(K-R A S)$, receptores de fator de crescimento ( $c$-ERBB2, $c-M E T$ e $K$-SAM), proteínas envolvidas na regulação do ciclo celular como TP53, APC, TP73 (mapeado em 1p36), CDKN1A (p27) e CCNE1 (ciclina E) ou proteínas de adesão (caderinas).

Várias alterações epigenéticas também atuam no processo multipassos da carcinogênese gástrica ${ }^{(70)}$. Por exemplo, na etapa inicial, detectou-se a ativação da telomerase, observada em vários casos de metaplasia intestinal e adenomas gástricos. Essa enzima é responsável pela adição de seqüências teloméricas às extremidades dos cromossomos, para compensar as perdas que ocorrem em cada divisão celular.

Os dados citogenéticos, que podem trazer importantes informações sobre as regiões do genoma envolvidas na malignização, são relativamente escassos nas lesões de estômago. Esse fato decorre, principalmente, das dificuldades de análise em metáfases obtidas em culturas de tumores primários. Mais recentemente, técnicas de citogenética molecular, como a hibridação in situ fluorescente (FISH) e a hibridação genômica comparativa (CGH), têm enriquecido esses dados e indicado o envolvimento de diferentes cromossomos e regiões cromossômicas nos processos de iniciação e progressão tumoral ${ }^{(21,32}$ 33,48,62). Ambas as técnicas estão baseadas na propriedade de hibridação de moléculas de ácidos nucléicos complementares. Utilizam DNAs ligados a compostos fluorescentes que, após o procedimento de hibridação, permitem a marcação de segmentos do genoma e a identificação daqueles com número anormal de cópias ou mesmo com alterações estruturais.

A técnica de $\mathrm{CGH}$, em função de suas características, tem revelado perdas e ganhos de diferentes segmentos. Os ganhos são mais freqüentes e envolvem, principalmente, as regiões 1q22-q31, 2q, 7pq, 8pq (8q23-qter), 9q33-qter, 13q, 17p11.2-q22, 18q e 20pq. Em especial, a banda 17q21 tem revelado alto nível de amplificação. As perdas afetam as regiões $4 q 32$ e $17 p$ e, menos freqüentemente, 1q, 5p, $9 p, 18 q$ e todo o cromossomo $21^{(36,38,56)}$

A técnica de FISH também tem auxiliado no mapeamento de genes e na elucidação de alterações cromossômicas não definidas pela citogenética clássica. Sua principal vantagem é o fato de permitir o estudo tanto de metáfases, como de núcleos interfásicos procedentes de células em cultura, tecidos frescos, material de arquivo emblocado em parafina e aspirado celular. Os resultados obtidos por essa técnica em tumores gástricos têm revelado, como no caso da $\mathrm{CGH}$, grande número de alterações cromossômicas numéricas. O ganho dos cromossomos 1, 2, 4, 7 e 20 é observado em estágios precoces da carcinogênese gástrica ${ }^{(16,32,46)}$. Por outro lado, trissomias e polissomias dos cromossomos 3, 6-8, 10-12, 15-17 e das regiões 7q31, 8q24, 9p21, 9p22-pter e 9p32-33 parecem estar relacionadas com transformação maligna e com invasão ou com tempo curto de sobrevida $^{(4,26,32,56,60,62)}$. Alguns dos genes presentes nessas regiões incluem os protooncogenes $c-M E T, c-M Y C$ e $c-E R B B 2$ e os supressores de tumor $C D K N 2 A, C D K N 2 B$ e $T P 53^{(23,26,44,56,60)}$, esses últimos responsáveis pela regulação do ciclo celular.

As regiões 7q31 e 17p13.1 estão entre as mais afetadas. Na região $7 q 31$ está mapeado o gene $c-M E T$, que codifica um receptor de fator de crescimento (HGF) envolvido no controle da proliferação de células do fígado e do trato gastrointestinal e, provavelmente, é importante no reparo da mucosa danificada ${ }^{(65)}$. Na região 17 p13.1 está localizado 
o supressor de tumor TP53. A mutação ou a perda desse gene é evento inicial na tumorigênese gástrica ${ }^{(23)}$ e também tem sido observada em lesões benignas ou pré-cancerosas, como gastrite atrófica, metaplasia intestinal e displasia. Seu produto tem papel essencial na regulação da proliferação celular e, em presença de lesões no DNA, é responsável pelo bloqueio do ciclo celular entre as fases G1-S. Nos casos em que o DNA não é reparado adequadamente, a proteína p53 ativa o processo de apoptose por meio da regulação transcricional e da interação direta com as proteínas bcl-2 e bax.

Ainda não está esclarecido se as alterações no gene TP53 são desencadeadas pela inflamação provocada pelo H. pylori. Entretanto, DEGUCHI et al. ${ }^{(13)}$ observaram freqüências mais elevadas de mutações no TP53 em pacientes com câncer gástrico infectados pelo H. pylori cagA+ do que nos grupos $H$. pylori-positivo/cagA-negativo e H. pylorinegativo.

Existem também indicações de que a infecção crônica pelo $H$. pylori é responsável pela instabilidade genômica observada em alguns casos de gastrite atrófica crônica e pelo aumento da proliferação celular $^{(24,39)}$ e da apoptose na mucosa gástrica, provavelmente em consequiência da resposta inflamatória ${ }^{(29)}$. Tem sido sugerido que a erradicação da infecção reverte o processo inflamatório e, conseqüentemente, a atrofia, a metaplasia e a instabilidade genômica $^{(7,18,24,39,46)}$.

A proliferação celular na mucosa gástrica de indivíduos $H$. pyloripositivo ocorre independentemente da cepa ser $\operatorname{cag} A$-positiva, mas a taxa de apoptose é significativamente maior nos indivíduos infectados por essa cepa ${ }^{(43)}$. Tal conclusão é, porém, controversa, sendo apoiada por alguns estudos realizados com cultura celular ${ }^{(51,53)}$, mas não por outros ${ }^{(69)}$.

Em conclusão, parece que a infecção provocada pelo $H$. pylori atua como co-fator na carcinogênese gástrica, favorecendo o aparecimento de danos no DNA e alterando os processos de proliferação celular e apoptose. A somatória desse e de outros fatores ambientais, juntamente com a suscetibilidade genética, deve facilitar o aparecimento de alterações genéticas somáticas que acompanham a evolução de lesões pré-cancerosas a câncer gástrico, mas muitos estudos são ainda necessários para a devida avaliação da verdadeira importância e do grau de participação de cada um desses fatores nas diferentes etapas da tumorigênese.

\section{COMENTÁRIOS FINAIS}

A carcinogênese gástrica é um processo com múltiplas etapas, em que as mudanças morfológicas são conseqüência das alterações genéticas, que ocorrem sucessivamente durante esse processo e podem levar à evolução de gastrite crônica em atrófica, associada ou não à metaplasia. Até essa etapa, as alterações na forma da célula e do núcleo podem ser revertidas, muitas vezes, após tratamento da infecção pelo $H$. pylori e mudanças na dieta e no estilo de vida. Todavia, parcela dessas gastrites atróficas associadas à metaplasia podem evoluir para displasia e, conseqüentemente, para o carcinoma in situ.

Muitas alterações genéticas observadas em lesões metaplásicas e adenomas são encontradas nas neoplasias gástricas, demonstrando a sua heterogeneidade ao longo do processo de malignização.

Os critérios histopatológicos são extremamente importantes para definir e dar suporte ao diagnóstico e prognóstico, todavia são limitados e subjetivos, gerando muitas vezes discordância entre observadores diferentes, principalmente quanto às lesões displásicas e carcinoma in situ. Por exemplo, os patologistas japoneses, ao contrário dos ocidentais, não consideram a existência de lesões displásicas, o que confunde os clínicos.

Tais dificuldades apontam para a necessidade de classificação que utilize critérios menos subjetivos. Os avanços na área molecular abrem a possibilidade de utilização de marcadores genéticos que, somados aos dados histopatológicos e imunohistoquímicos poderá levar a diagnósticos e prognósticos mais seguros.

César ACG, Silva AE, Tajara EH. Genetics and environmental factors in gastric carcinogenesis. Arq Gastroenterol 2002;39(4):253-259.

ABSTRACT - Background - Gastric cancer is considered to be the second most common cancer worldwide. Carcinogenesis of the stomach is a multi-stage process. The progression from normal epithelial to tumor cells may involve at least five stages: superficial gastritis, chronic atrophic gastritis, intestinal metaplasia, dysplasia and carcinoma. These sequential changes in the gastric mucosa may occur over a period of many years as a result of exposure to a variety of exogenous and/or endogenous factors which cause genetic alterations. Recent developments in molecular genetics have shown that the accumulation of these multiple genetic alterations, including activation of oncogenes and inactivation of tumor-suppressor genes, results in cancer development. Genetic alterations previously reported in gastric carcinomas include amplifications or mutations of the $c$-ERBB2, K-RAS, $c$-MET and TP53. Chromosomal gains were also found in various combinations with chromosomal losses and may be associated with the overexpression of dominant oncogenes contributing to tumor progression. Conclusions - These accumulated genetic changes in carcinomas provide evidences for the stepwise mode of gastric carcinogenesis through the accumulation of a series of genetic alterations.

HEADINGS - Stomach neoplasms, genetics. 


\section{REFERÊNCIAS BIBLIOGRÁFICAS}

1. AICR - American Institute for Cancer Research. World Cancer Research Fund Food, nutrition and the prevention of cancer: a global perspective. Washington, DC: Banta Book Group; 1997.

2. Anand BS, Graham DY. Ulcer and gastritis. Endoscopy 1999;31:215-25.

3. Atherton JC, Cao P, Peek RM, Tummuru MKR, Blaser MJ, Cover TL. Mosaicism in vacuolating cytotoxin alleles of Helicobacter pylori: association of specific vacA types with cytotoxin production and peptic ulceration. J Biol Chem 1995;270:17771-7.

4. Blanco R, Lyda M, Davis B, Kraus M, Fenoglio-Preiseer C. Trisomy 3 in gastric lymphomas of extranodal marginal zone-B cell (mucosa-associated lymphoid tissue) origin demonstrated by FISH in intact paraffin tissue sections. Human Pathol 1999:30:706-11.

5. Brien TP, Depowski MD, Sheehan CE, Ross JS, McKenna BJ. Prognostic factors in gastric cancer. Mod Pathol 1998;11:870-7.

6. Buonsanti G, Calistri D, Padovan L. Microsatellite instability in intestinal- and diffuse-type gastric carcinoma. J Pathol 1997;182:167-73.

7. Cahill RJ, Xia H, Kilgallen C, Beattie S, Hamilton H, O'Morain C. Effect of eradication of Helicobacter pylori infection on gastric epithelial cell proliferation. Dig Dis Sci 1995;40:1627-31.

8. Chan AO, Lam SK, Chu KM, Lam CM, Kwok E, Leung SY, Yuen ST, Law SY, Hui WM, Lai KC, Wong CY, Hu HC, Lai CL, Wong J. Soluble E-cadherine is a valid prognostic marker in gastric carcinoma. Gut 2001;48:808-11.

9. Cheli R, Giacosa A. Atrophic gastritis. In: Sherlock P, Morson BC, Barbara L, Veronesi U. editors. Precancerous lesions for the gastrointestinal tract. New York: Raven Press; 1983.

10. Cho KR, Vogelstein B. Genetic alterations in the adenoma-carcinoma sequence. Cancer 1992;70:1727-31.

11. Cotran RS, Kumar V, Collins T. Pathologic basis of disease. 6 ed. Philadelphia: W.B. Saunders; 1999.

12. Dani R. Gastroenterologia essencial. Rio de Janeiro: Guanabara; 1998.

13. Deguchi R, Takagi A, Kawata H, Inoko H, Miwa T. Association between CagA+ Helicobacter pylori infection and $\mathrm{p} 53$, bax and transforming growth factor-betaRII gene mutations in gastric cancer patients. Int J Cancer 2001;91:481-5.

14. De Vita VT Jr, Hellman S, Rosenberg SA. Cancer - Principles and practice of oncology. 5. ed. Philadelphia: Lippincott-Raven; 1997. v.1.

15. Endoh Y, Sakata K, Tamura G, Ohmura K, Ajioka Y, Watanabe H, Motoyama T Cellular phenotypes of differentiated-type adenocarcinomas and precancerous lesions of the stomach are dependent on the genetic pathways. J Pathol 2000;191:257-63.

16. Espinoza LA, Neto BJ, Casartelli C. Pathological and karyotypic abnormalities in advanced gastric carcinomas. Cancer Genet Cytogenet 1999;109:45-50.

17. Fearon ER, Vogelstein B. A genetic model for colorectal tumorigenesis. Cell 1990;61:759-67.

18. Fraser AG, Sim R, Sankey EA, Dhillon AP, Pounder RE. Effect of eradiction of Helicobacter pylori on gastric epithelial cell proliferation. Aliment Pharmacol Ther 1994;8:167-73.

19. Genta RM. Helicobacter pylori as a promotor of intestinal metaplasia and gastric cancer: an alluring hypothesis in search of evidence. Eur J Gastroenterol Hepatol 1995; $7:$ S25-S30.

20. Genta RM. Gastric atrophy and atrophic gastritis - nebulous concepts in search of a definition. Aliment Pharmacol Ther 1998;12:17-23.

21. Guan XY, Fu SB, Xia JC, Fang Y, Sham JST, Du BD, Zhou H, Lu S, Wang BQ, Lin YZ, Liang Q, Lim XM, Ju B, Ning XM, Du JR, Lim P, Trent JM. Reccurent chromosome changes in 62 primary gastric carcinomas detected by comparative genomic hybridization. Cancer Genetic Cytogenetic 2000;123:27-34.

22. Hansson L, Nyren O, Hsing AW. The risk of stomach cancer in patients with gastric or duodenal ulcer disease. N Engl J Med 1996;335:242-9.

23. Hao Y, Zhang J, Yi C, Qian W. Abnormal change of p53 gene in gastric and precancerous lesions and APC gene deletion in gastric carcinoma and near tissues. J Tongji Med Univ 1997; 17:75-8.

24. Hibi K, Mitomi H, Koizumi W, Tanabe S, Saigenji K, Okayasu I. Enhanced cellular proliferation and $\mathrm{p} 53$ accumulation in gastric mucosa chronically infected with Helicobacter pylori. Am J Clin Pathol 1997;108:26-34.

25. Holcombe C. Helicobacter pylori: the African enigma. Gut 1992;33:429-31.

26. Igaki H, Sasaki H, Tachimori Y, Kato H, Watanabe H, Kimura T, Harada Y, Sugimura T, Terada M. Mutation frequency of the p16/CDKN2 gene in primary cancers in the upper digestive tract. Cancer Res 1995;55:3421-3.

27. INCA - Instituto Nacional do Câncer. Estimativa da incidência e mortalidade por câncer no Brasil. Rio de Janeiro; 2002.

28. Ito Y, Azuma T, Ito S, Suto H, Miyaji H, Yamazaki Y, Kato T, Kohli Y, Keida Y, Kuriyama M. Sequence analysis and clinical significance of the iceA gene from Helicobacter pylori strains in Japan. J Clin Microbiol 2000;38:483-8.
29. Jang TJ, Kim JR. Proliferation and apoptosis in gastric antral epithelial cells of patients infected with Helicobacter pylori. J Gastroenterol 2000;35:265-71.

30. Jass JR, Filipe MI. Variants of intestinal metaplasia associated with gastric carcinoma. A histochemical study. Histopathology 1997;3:191-9.

31. Kim YH, Kim NG, Lim JG, Park C, Kim H. Chromosomal alterations in paired gastric adenomas and carcinomas. Am J Pathol 2001;158:655-62.

32. Kitayama Y, Igarashi H, Sugimura H. Different vulnerability among chromosomes to numerical instability in gastric carcinogenesis: stage-dependent analysis by FISH with the use of microwave irradiation. Clin Cancer Res 2000;6:3139-46.

33. Kobayashi K, Okamoto T, Takayama S, Akiyama M, Ohono T, Yamada H. Genetic instability in intestinal metaplasia is a frequent event leading to well-differentiated early adenocarcinoma of the stomach. Eur J Cancer 2000;36:1113-9.

34. Kokkola A, Haapiainen R, Laxen F, Puolakkaninen P, Kivilalkso E, Virtamo J Sipponen P. Risk of gastric carcinoma in patients with mucosal dysplasia associated with atrophic gastritis: a follow-up study. J Clin Pathol 1996;49:979-84.

35. Kono S, Hirohata T. Nutrition and stomach cancer. Cancer Causes Control 1996; 7:41-55

36. Koo SH, Kwon KC, Shin SY, Jeon YM, Park JW, Kim SH, Noh MS. Genetic alterations of gastric cancer: comparative genomic hybridization and fluorescence in situ hybridization studies. Cancer Genet Cytogenet 2000;117:97-103.

37. Kuipers EJ. Exploring the link between Helicobacter pylori and gastric cancer. Aliment Pharmacol Ther 1999;13:3-11.

38. Larramendy ML, El-Rifai W, Kokkola A, Puolakkainen P, Monni O, Salovaara $\mathrm{R}$, Aarnio M, Knuutila S. Comparative genomic hybridization reveals differences in DNA copy number changes between sporadic gastric carcinomas and gastric carcinomas from patients with hereditary nonpoluposis colorectal cancer. Cancer Genet Cytogenet 1998;106:62-5.

39. Lynch DAF, Mapstone NP, Clarke AMT, Jackson P, Moayyedi R, Dixon MF, Quirke P, Axon ATR. Correlation between epithelial cell proliferation and histological grading in gastric mucosa. J Clin Pathol 1999;52:367-71.

40. Ma JL, You WC, Gail MH, Zhang L, Blot WJ, Chang YS, Jiang J, Liu WD, Hu YR, Brown LM, Xu GW, Fraumeni JF Jr. Helicobacter pylori infection and mode of transmission in a population at high risk of stomach cancer. Int J Epidemiol 1998;27:570-3.

41. Maeta M, Saito H, Oka S, Tsujitani S, Ikeguchi N, Kaibara N. Mutated p53 in tumors, mutant p53 and p53-specific antibodies in the circulation in patients with gastric cancer. J Exp Clin Cancer Res 2000;19:489-95.

42. Ming SC, Hirota T. Malignant epithelial tumors of the stomach. In: Ming SC, Goldman H, editors. Pathology of the gastrointestinal tract. 2 ed. Baltimore: Williams \& Wilkins; 1998. p.607-47.

43. Moss SF, Sordillo EM, Abdalla AM, Makarov V, Hanzely Z, Perez-Perez G, Blaser MJ, Holt PR. Increased gastric epithelial cell apoptosis associated with colonization with cagA+ Helicobacter pylori strains. Cancer Res 2001;61:1406-11.

44. Nakajima M, Sawada H, Yamada Y, Watanabe A, Tatsumi M, Yamashita J, Matsuda M, Sakaguchi T, Hirao T, Nakano $\mathrm{H}$. The prognostic significance of amplification and overexpression of c-met and c-erbB-2 in human gastric carcinomas. Cancer 2000;88:1894-902.

45. Nakamura K, Sugano H, Takagi K. Carcinoma of the stomach in incipient phase: its histogenesis and histological appearance. Jpn J Cancer Res 1968;69:930-5.

46. Nardone G, Staibano S, Rocco A, Mezza E, D'Armiento FP, Insabato L, Coppola A, Salvatore G, Lucariello A, Figura N, De Rosa G, Budillon G. Effect of Helicobacter pylori infection and its eradication on cell proliferation, DNA status, and oncogene expression in patients with chronic gastritis. Gut 1999;44:789-99

47. Oashima H, Friesen M, Malaveille C, Brouet I, Hautefeuille A, Bartsch H. Formation of direct-acting genotoxic substances in nitrosated smoked fish and meat products: identification of simple phenolic precursors and phenyldiazonium ions as reactive products. Food Chem Toxicol 1989;27:193-200.

48. Okada K, Sugihara H, Bamba M, Bamba T, Hattori T. Sequential numerical changes of chromosomes 7 and 18 in diffuse-type stomach cancer cell lines: combined comparative genomica hybridization, fluorescence in situ hybridization and ploidy analyses. Cancer Genet Cytogenet 2000;118:99-107.

49. Park WS, Oh RR, Park JY, Shin MS, Lee HK, Lee SH, Yoo NJ, Lee JY. Absence of mutations in the kinase domain of the Met gene and frequent expression of Met and HGF/SF protein in primary gastric carcinomas. APMIS 2000;108:195-200.

50. Peek RM Jr, Thompson SA, Donahue JP, Tham KT, Atherton JC, Blaser MJ, Miller GG. Adherence to gastric epithelial cells induces expression of a Helicobacter pylori gene, iceA, that is associated with clinical outcome. Proc Assoc Am Physicians 1998;110:531-44.

51. Peek RM, Blaser MJ, Mays DJ, Forsyth MH, Cover TI, Song SY, Krishnan U, Pietenpol JA. Helicobacter pylori strain-specific genotypes and modulation of the gastric epithelial cell cycle. Cancer Res 1999;59:6124-31. 
52. Poremba C, Uandell DW, Huang Q, Little JB, Mellin W, Schmid KW, Bocker W, Dockhorn-Dworniczak B. Frequency and spectrum of p53 mutations in gastric cancer: a molecular genetic adn immunohistochemical study. Virchows Arch 1995;426:447-55.

53. Rudi J, Kuck D, Strand S, von Herbay A, Mariani SM, Krammer PH, Galle PR, Stremmei W. Involvement of the CD95 (APO-1/Fas) receptor and ligand system in Helicobacter pylori-induced gastric epithelial apoptosis. J Clin Invest 1998;102:1506-14.

54. Russo A, Bazan V, Migliavacca M, Tubiolo C, Macaluso M, Zanna I, Corsale S, Latteri F, Valerio MR, Pantuso G, Morello V, Dardanoni G, Latteri MA, Colucci G, Tomasino RM, Gebbia N. DNA aneuploidy and high proliferative activity but not K-ras-2 mutations as independent predictors of clinical in operable gastric carcinoma: results of a 5-year Gruppo Oncologico dell' Italia Meridonale (GDIM) prospective study. Cancer 2001;92:294-302.

55. Safatle-Ribeiro A, Ribeiro U, Reynolds JC. Gastric stump cancer: What is the risk? Dig Dis 1998;16:159-68.

56. Sakakura C, Mori T, Sakabe T, Ariyama Y, Shinomiya T, Date K, Hagiwara A, Yamaguchi T, Takahashi T, Nakamura Y, Abe T, Inazawa J. Gains, losses and amplifications of genomic materials in primary gastric cancers analyzed by comparative genomic hybridization. Genes Chromosomes Cancer 1999;24:299305.

57. Shiao YH, Rugge M, Correa P, Lehmann HP, Scheer WD. p53 alteration in gastric precancerous lesions. Am J Pathol 1994;144:511-7.

58. Sierra R, Munoz N, Pena AS. Antibodies to Helicobacter pylori and pepsinogen levels in children in Costa Rica. Cancer Epidemiol Biomark Prevent 1992;1:44954.

59. Sipponen P, Kekki M, Siurala M. Precancerous conditions. In: Filipe MI, Jass JR, editors. Gastric cancer. Current problems in tumour pathology. London: Churchill Livingstone; 1985. p. 152-71.

60. Tahara E. Molecular mechanisms of stomach carcinogenesis. J Cancer Res Clin Oncol 1993;119:265-72.

61. Tahara E. Molecular mechanism of human stomach carcinogenesis implicated in Helicobacter pylori infection. Exp Toxicol Pathol 1998;50:375-8.
62. Takahashi Y, Shintaku K, Ishii Y, Asai S, Ishikawa K, Fujii M. Analysis of MYC and chromosome 8 copy number changes in gastrointestinal cancers by dual-color fluorescence in situ hybridization. Cancer Genet Cytogenet 1998;107:61-4.

63. Takahashi Y, Nagata T, Sataoshi A, Shintaku K, Eguchi T, Ishii Y, Fujii M, Ishikawa K. Detection of aberrations of $17 \mathrm{p}$ and $\mathrm{p} 53$ gene in gastrointestinal cancers by dual (two-color) fluorescence in situ hybridization and genechip p53 assay. Cancer Genet Cytogenet 2000;121:38-43.

64. Takano Y, Kato Y, van Diest PJ, Masuda M, Mitomi HC, Okayasu I. Cyclin D2 overexpression and lack of $\mathrm{p} 27$ correlate positively and cyclin E inversely with a poor prognosis in gastric cancer cases. Am J Pathol 2000;156:585-94

65. Tarasova NI, Rulong S, Oskarsson M. Cellular localization of met and its ligand hepatocyte growth factor/scatter factor in human stomach epithelium. Gastroenterology 1996;110:1125.

66. Tytgat G.N. Helicobacter pylori in man: problems to be solved. Dig Dis 1998;16:192-7.

67. van Doorn LJ, Figueiredo C, Sanna R, Plaisier A, Schneeberger P, Boer W, Quint W. Clinical revelance of the cagA, vacA and iceA status of Helicobacter pylori. Gastroenterology 1998;115:58-66.

68. Yasui W, Yokozaki H, Fujimoto J, Naka K, Kuniyasu H, Tahara E. Genetic and epigenetic alterations in multistep carcinogenesis of the stomach. J Gastroenterol 2000;35:111-5.

69. Yasui W, Oue N, Kuniyasu H, Ito R, Tahara E, Yokozaki H. Molecular diagnosi of gastric cancer: present and future. Gastric Cancer 2001;4:113-21.

70. Ward MH, Sinha R, Heineman EF. Risk of adenocarcinoma of the stomach and esophagus with meat cooking method and doneness preference. Int J Cancer 1997;71:14-9.

71. Werner M, Becker KF, Keller GC, Hofler H. Gastric adenocarcinoma: pathomorphology and molecular pathology. J Cancer Res Clin Oncol 2001;127:207-16

Recebido em 8/1/2002. Aprovado em 13/8/2002 